\title{
Disadvantages of using Traditional, Interactive and Distance Learning Methods when Studying the Specialty "Pharmacy"
}

\author{
Mariia Sergeevna Soboleva* \\ Doctor of Pharmaceutical Sciences, Professor of the Department Pharmacy and Pharmacology, \\ The Far Eastern State Medical University, 35, Muravyev-Amursky St., Khabarovsk - 680000, \\ Russian Federation; martimser@mail.ru
}

\begin{abstract}
Interactive and remote technologies are being actively introduced into the training process in the specialty "Pharmacy." In addition to ease of use, they have several advantages and disadvantages for all stakeholders. The purpose of the work is to analyze the disadvantages of traditional, interactive, and remote methods of teaching in the specialty "Pharmacy" at the Far Eastern State Medical University. This is a sociological survey of students of the Faculty of Pharmacy and Biomedicine (higher education), as well as the Medical-Pharmaceutical College (secondary education). Statistical processing was performed using the non-parametric Mann-Whitney, Kruskal-Wallis, Spearman's rank correlation coefficient. Traditional teaching methods are characterized by the inconvenience of tight time frames. During on-line classes, it is more difficult to use an individual methodology for the student and change the teaching method. The most characteristic shortcomings of distance learning include the lack of motivation and the possibility of violations (writing off, forgery, etc.) by the student. Despite the geographical remoteness of the regions, material, and technical difficulties in switching to distance learning, as a rule, did not arise. The lack of an individual approach and the subjectivity of student assessments in distance and traditional teaching methods are due to the high occupancy of groups and their frequent combination (10-25 people) during the class. The disadvantage of remote methods is the complexity of regular control by the teacher, the lack of secure personality identification systems when sending written works and testing on-line, and the low level of consciousness of future specialists. According to the results of the questionnaire, the least number of shortcomings have interactive teaching methods, implying the active participation of the student himself and an individual approach.
\end{abstract}

Keywords: Education, Interactive Classes, Pharmacy, Remote Technologies, Traditional Training

\section{Introduction}

Application of various methods of training is a necessary condition of formation of knowledge, abilities, skills, and competencies of the specialists. Traditional teaching methods, such as lectures, seminars, laboratories are the main ones in obtaining higher education in the specialty "Pharmacy," due to the large number of specialized disciplines and the need for professional equipment. However, interactive and distance learning methods are actively used, including advanced training and practical works, and their effectiveness is analyzed ${ }^{1}$. The experience of virtual practice and the usage of digital technologies ${ }^{2}$ are evaluated. There is interesting experience of using the mixed learning's in Australia: online recorded lectures, self-study, teleconference seminars and a two-day intensive complex on campus ${ }^{3}$.

Thus, according to the results of a meta-analysis conducted in Italy, telepharmacy is used to support clinical services, distance learning and consultations of

*Author for correspondence 
"special pharmacies," as well as for the prescription and coordination of drug therapy ${ }^{4}$. In Spain, telepharmacy practices include therapeutic validation, clinical drafting, pharmaceutical care, therapeutic surveillance, adherence monitoring, drug education and information, coordination among healthcare professionals, and evaluation of therapy outcomes ${ }^{5}$. Telemedicine is being actively introduced for conferences, in the diagnosis and treatment of patients, a charity organization " 4 All International" has been created for patients living in remote regions ${ }^{6}$.

The results of a survey of students $(\mathrm{n}=700)$ and teachers $(\mathrm{n}=74)$ in Saudi Arabia demonstrated the difficulties of implementing scientific concepts in virtual classrooms, the lack of interaction between students and teachers, the need to use alternative assessment methods ${ }^{7}$. Another problem of distance learning was the difficulties of interaction between colleagues, and the performance of scientific work ${ }^{8}$.

The study data in Jordan $(\mathrm{n}=382)$ demonstrated that most teachers had moderate to high motivation for distance learning including in conditions of SARS$\mathrm{CoV}-2$ infection. At the same time, $31,4 \%$ of respondents had a severe psychological status disorder (stress), and $38,2 \%$ - from mild to moderate ${ }^{9}$. A survey of 730 students showed that only a third of respondents preferred remote electronic exams. The most convenient form of remote examination was a quiz, compared to reports or written assignments. One of the main problems of remote exams was called unscrupulous students ${ }^{10}$.

The largest numbers of studies about distance learning were conducted in the United States. Applied experience of simulation inter professional education and telemedicine technology based on simulation using robot ${ }^{11}$, simulation of emergency medical care in children using remote assistance ${ }^{12}$, audience questioning system through mobile applications (ARS) during lectures and classes ${ }^{13}, 3$-station remote Objective Structured Clinical Examination $(\text { OSCEs })^{14,15}$, pharmacy simulation software ${ }^{16}$. Digital technologies and smartphones have been used for biomedical research, where the main problem is the retention times the participants. The main factors of patient retention in such a study are recommending from a doctor, participation compensation, the presence of a clinical condition, old age ${ }^{17}$.

The forced transition to a distance learning form in 2020 was quite controversial, both for the teachers and for the students themselves ${ }^{18,19}$. This experience, for such a quantity of students, was the first for many educational organizations, including the Far Eastern State Medical University (FESMU) - the first medical university in the Far Eastern Federal District (FSD), one of the largest medical educational institutions in FSD. The purpose of the study is to analyze the disadvantages of traditional, interactive, and remote methods of training in the specialty "Pharmacy" at the FESMU.

\section{Materials and Methods}

Sociological survey of students of the Far Eastern State Medical University of the Faculty of Pharmacy and Biomedicine (higher education, term of study 5 years) in the specialty 33.05.01 "Pharmacy" ( $\mathrm{n}=140$ ), as well as students of the medical-pharmaceutical college (secondary education, term of study 2 years 10 months) in the specialty 33.02.01 "Pharmacy" $(\mathrm{n}=127)$. The total sample was 267 respondents. The survey was conducted using the questionnaire method using the Google Forms service (https://www.google.ru/intl/ru/forms/about/), the primary material was processed in Microsoft Excel 365, using the Data Analysis package - descriptive statistics. Statistical processing of the obtained data was carried out using IBM SPSS Statistics 25. Comparison of the two independent samples was performed using a non-parametric Mann-Whitney test. Comparison of three independent samples was carried out using the nonparametric Kruskal-Wallis test. The null distribution equality hypothesis deviated at an asymptotic significance of less than 0,05. Correlation of different learning methods with the level of education was calculated using the Spearman's rank correlation coefficient. The correlation was considered valid with significance (two-sided) less than 0,05 . The upper and lower limits were calculated for the correlation coefficient. To assess the reliability of the questionnaire, the Cronbach's alpha was calculated. The number of items for analysis (response options) was 27. The obtained value $\alpha=0,897$, which is sufficient, when conducting a sociological survey.

\section{Results}

The distribution of respondents' responses is shown in Figures 1-3.

There were no reliable differences and correlations in the distribution of respondents' responses depending 


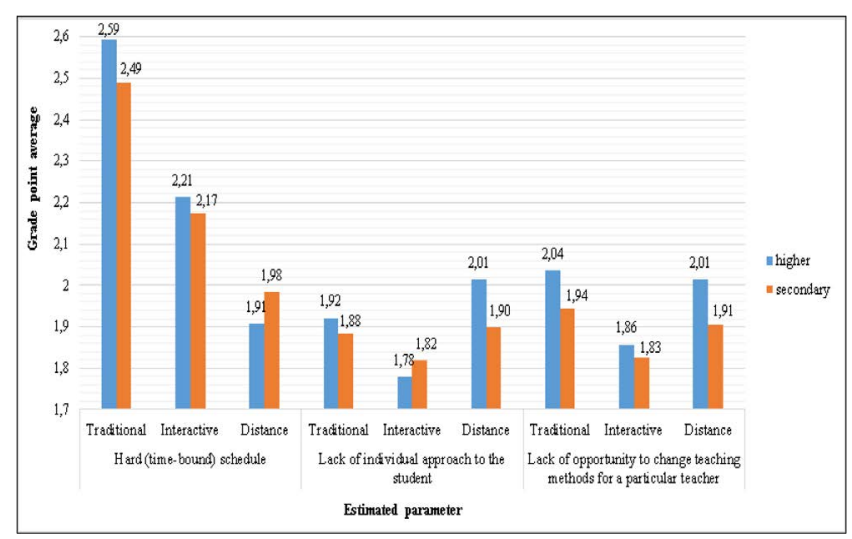

Figure 1. Disadvantages of traditional, interactive, and distance methods of teaching in the specialty "Pharmacy" (Part 1).

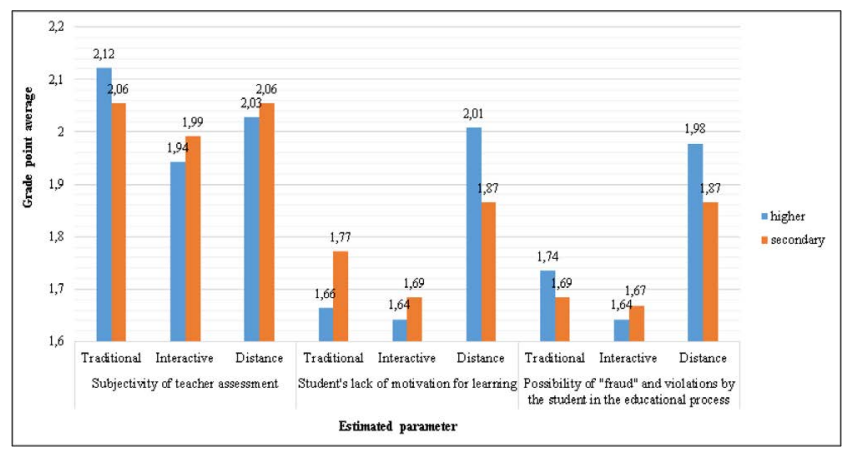

Figure 2. Disadvantages of traditional, interactive, and remote distance of teaching in the specialty "Pharmacy" (Part 2).

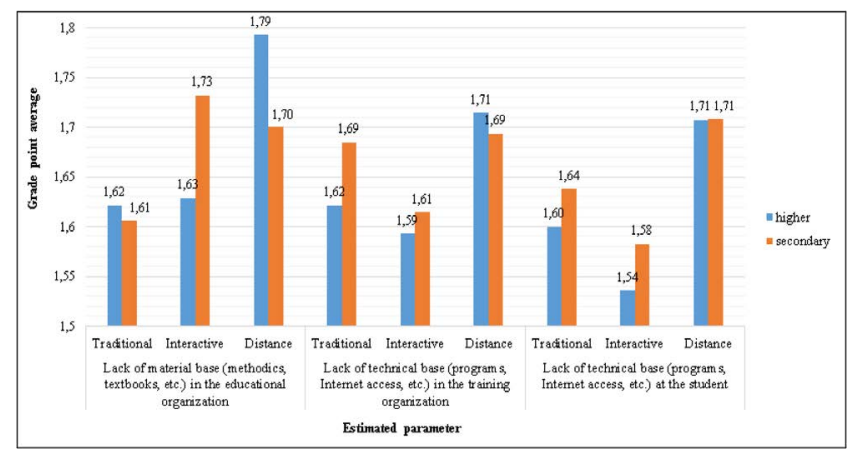

Figure 3. Disadvantages of traditional, interactive, and distance methods of teaching in the specialty "Pharmacy" (Part 3).

on the level of training according to the parameters estimated. Traditional teaching methods are characterized by tight time frames. Based on the curriculum, a schedule is drawn up according to which further training takes place. Some distance classes (for example, lectures) can be recorded in advance, and then the link is proved for familiarize students with the materials, so this drawback is least characteristic of remote methods. The difference in average scores was 0,68 and 0,51 , respectively.

During online classes, it is more difficult to use an individual approach due to the lack of direct "contact" work. The least disadvantage is in interactive methods. Analysis of the situation or role-playing game is carried out with the participation of specific students and their knowledge, and skills. The difference between the average scores was 0,31 and 0,1 points, respectively.

Respondents' assessment of the inability to change teaching methods was comparable in all learning methods from 2,04-1,83. The obtained data are natural, due to a significant degree of subjectivity in the teaching process, depending on the specifics of the discipline, demanding and experience of faculty.

The least subjectivity of assessments is observed when implementing interactive methods - less than 2 points and the most - in traditional ones, which is predictable, based on the data of the lack of an individual approach to training. The most discussed disadvantages of distance learning include the lack of motivation (2.01 and 1.87 points, respectively) and the possibility of violations (write-off, forgery, etc.) by the student (1,98 and 1,87 points). Traditional and interactive learning methods are more preferred in terms of the parameters to be evaluated.

The next set of questions focused on the material and the technical side of the process many students of FESMU in connection with the COVID-19 pandemic were forced to leave the university and study directly at the place of residence, that is, in all regions of the FSD. Many regions and municipalities are characterized by low population density (from 0,1 people per $\mathrm{km}^{2}$ in the Chukotka Autonomous Okrug to 11,6 people per $\mathrm{km}^{2}$ in the Primorsky region $)^{20}$ and the lack of a full-fledged broadband Internet. In addition, the situation was complicated by the geographical length of the regions of the FSD in 3 time zones, which led to the need to adjust the training schedule on-line. The material and technical disadvantages that arose certainly affected the educational process, however, the average score of these shortcomings was less than 2 - less than partially characteristic. The most significant disadvantages include the absence/ obsolescence of the material base - up to 1,79 (manuals, textbooks, equipment, consumables), imperfections of technical capability at the university and at the student up to 1,71 points. 
Integral assessment (ranking) of all analyzed shortcomings of the educational process in the specialty "Pharmacy" is presented in Figure 4. The least convenient is the time-bound schedule, and the least common is the lack of technical ability of the student.

Integral assessment of analyzing the shortcomings of traditional, interactive and distance training methods is presented in Figure 5. No statistically significant differences were found in the assessment of respondents $(\mathrm{p}=0,085)$. Despite convenience and safety, distance learning methods were assessed as having the most deficiencies - 1,88 , and the least negative estimates were observed in interactive - 1,77.

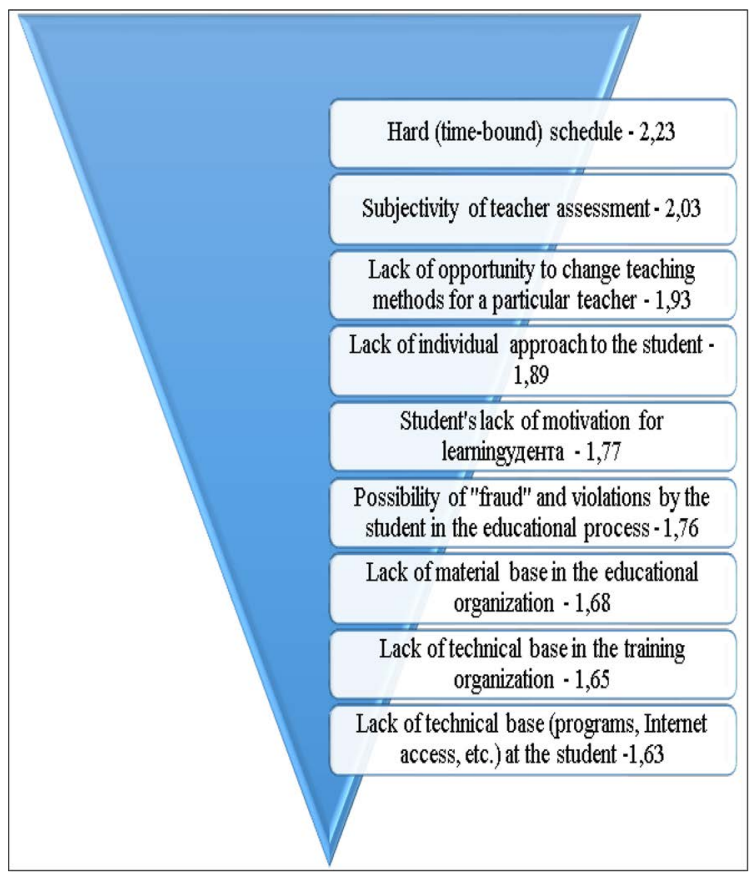

Figure 4. Integral assessment of the disadvantages of the training process in the specialty "Pharmacy".

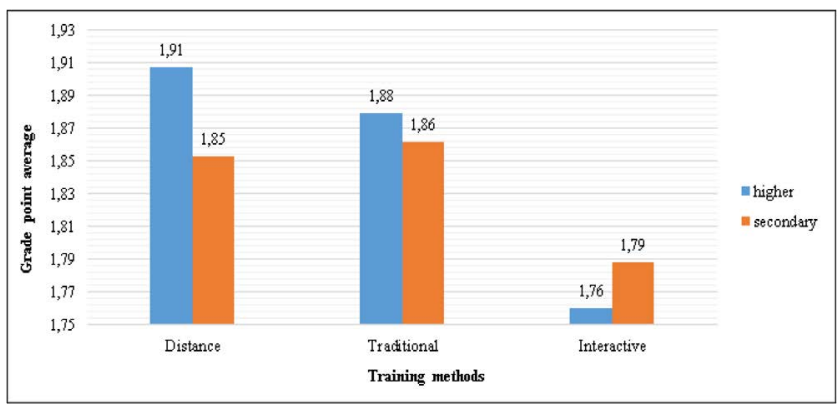

Figure 5. Integral assessment of disadvantages of traditional, interactive and distance methods of training in the specialty "Pharmacy".

\section{Discussion}

The highest score of a "hard" schedule in traditional teaching methods can be explained by the frequent combination of study and work, especially in senior students. The lack of an individual approach and the subjectivity of the teacher's assessments in distance and traditional teaching methods is due to the high occupancy of groups and their frequent combination (from 10 to 25 people) during classes. In the case of an interactive class, each student or group of students is given an individual task, which allows more adaptation of the educational process. The subjectivity of estimates is also the least characteristic of interactive teaching methods, since the student acts as an active participant in the educational process in the presence of his colleagues, that is, publicity.

Among the most significant shortcomings of distance learning methods, respondents called the lack of motivation for learning and the possibility of violations by students. The data obtained can be explained by the complexity of regular control by the teacher, the lack of secure identity identification systems when sending written works and testing on-line, the low level of consciousness of future specialists, which, of course, requires active career guidance work and tighter control by the faculty.

The problems of the lack of material and technical base at the educational organization and at students were less significant for all teaching forms, however, they were most pronounced for distance ones. These shortcomings are most easily addressed in the institution itself by upgrading and developing new software, improving electronic databases, and ensuring access to them.

The forced transition of educational organizations to a format of remote training demonstrated a significant number of organizational, psychological, and logistical shortcomings, which affected the highest total score in assessing the analyzed parameters.

\section{Conclusion}

The most significant shortcomings of the training process when mastering the specialty "Pharmacy" include a "tough" (time-bound) schedule, the subjectivity of estimates, and the absence of an individual approach. The least significant shortcomings, according to respondents, are the lack of material and technical base. There were no statistically significant differences in the distribution 
of respondents' responses depending on the level of education received (higher or secondary). According to the results of the questionnaire, the smallest number of shortcomings is interactive teaching methods, implying the active participation of the student himself and an individual approach.

\section{Acknowledgments}

None.

Ethics: this article does not contain research involving humans or animals.

Financing: this study did not have any financial support from third parties.

Author's Contribution: author contributed equally to the research work.

Conflict of Interests: the author claims that there is no conflict of interest.

\section{References}

1. Paudyal V, Cadogan C, Fialová D, Henman MC, Hazen A, Okuyan B, Lutters M, Stewart D. Provision of clinical pharmacy services during the COVID-19 pandemic: Experiences of pharmacists from 16 European countries. Res Social Adm Pharm, 2020 Nov 30; S1551-7411(20)31202-X. https://doi.org/10.1016/j.sapharm.2020.11.017.

2. Jordan D, Guiu-Segura JM, Sousa-Pinto G, Wang LN. How COVID-19 has impacted the role of pharmacists around the world. Farm Hosp, 2021 Feb 22; 45(2):89-95. https:// doi.org/10.7399/fh.11652.

3. Cardiff LM, Lum EP, Mitchell C, Nissen LM, Patounas MP, McBride LJ. Teaching the principles of safe prescribing to a mixed profession postgraduate cohort: Program development. J Multidiscip Healthc, 2018 Oct 30; 11:635-644. 2018. https://doi.org/10.2147/JMDH.S169424.

4. Baldoni S, Amenta F, Ricci G. Telepharmacy services: Present status and future perspectives: A review. Medicina (Kaunas), 2019 Jul 1; 55(7):327. https://doi.org/10.3390/ medicina55070327

5. Morillo-Verdugo R, Margusino-Framiñán L, Monte-Boquet E, Morell-Baladrón A, Barreda-Hernández D, Rey-Piñeiro XM, Negro-Vega E, Delgado-Sánchez O. Spanish Society of Hospital Pharmacy Position Statement on Telepharmacy: Recommendations for its implementation and development. Farm Hosp, 2020 Jul 1; 44(4):174-181. https://doi. org/ 10.7399/fh.11515.

6. Shah TK, Tariq T, Phillips R, Davison S, Hoare A, Hasan SS, Babar ZU. Health care for all: effective, community supported, healthcare with innovative use of telemedicine technology. J Pharm Policy Pract., 2018 Feb 1; 11:3. https:// doi.org/10.1186/s40545-018-0130-5.

7. Alqurshi A. Investigating the impact of COVID-19 lockdown on pharmaceutical education in Saudi Arabia - A call for a remote teaching contingency strategy. Saudi Pharm J, 2020 Sep; 28(9):1075-1083. https://doi.org/10.1016/j. jsps.2020.07.008.

8. Al-Taweel D, Al-Haqan A, Bajis D, Al-Bader J, Al-Taweel AM, Al-Awadhi A, Al-Awadhi F. Multidisciplinary academic perspectives during the COVID-19 pandemic. Int J Health Plann Manage, 2020 Nov; 35(6):1295-1301. https:// doi.org/10.1002/hpm.3032.

9. Akour A, Al-Tammemi AB, Barakat M, Kanj R, Fakhouri HN, Malkawi A, Musleh G. The impact of the COVID19 pandemic and emergency distance teaching on the Psychological Status of University Teachers: A cross-sectional study in Jordan. Am J Trop Med Hyg, 2020 Dec; 103(6):2391-2399. Epub 2020 Oct 27. https://doi. org/10.4269/ajtmh.20-0877.

10. Elsalem L, Al-Azzam N, Jum'ah AA, Obeidat N. Remote E-exams during Covid-19 pandemic: A cross-sectional study of students' preferences and academic dishonesty in faculties of medical sciences. Ann Med Surg (Lond), 2021 Feb; 62:326-333. https://doi.org/10.1016/j. amsu.2021.01.054.

11. Scott A, Dawson RM, Mitchell S, Catledge C. Simulationbased interprofessional education in a rural setting: The development and evaluation of a "Remote-In" telehealth scenario. Nurs Educ Perspect, 2020 May/Jun; 41(3):187189. https://doi.org/10.1097/01.NEP.0000000000000461.

12. Ohta K, Kurosawa H, Shiima Y, Ikeyama T, Scott J, Hayes S, Gould M, Buchanan N, Nadkarni V, Nishisaki A. The effectiveness of remote facilitation in simulation-based pediatric resuscitation training for medical students. Pediatr Emerg Care, 2017 Aug; 33(8):564-569. https://doi.org/10.1097/ PEC.0000000000000752.

13. Koval PG, Kim JJ, Makhlouf T. Pharmacist perception of a mobile application audience response system for remote pharmacy continuing education participants. J Pharm Pract, 2020 Apr; 33(2):153-157. https://doi. org/10.1177/0897190018792391.

14. Savage A, Minshew LM, Anksorus HN, McLaughlin JE. Remote OSCE experience: What first year pharmacy students liked, learned, and suggested for future implementations. Pharmacy (Basel), 2021 Mar 18; 9(1):62. https:// doi.org/10.3390/pharmacy9010062.

15. Scoular S, Huntsberry A, Patel T, Wettergreen S, Brunner JM. Transitioning competency-based communication assessments to the online platform: Examples and student 
outcomes. Pharmacy (Basel), 2021 Mar 5; 9(1):52. https:// doi.org/10.3390/pharmacy9010052.

16. Reynolds PM, Rhein E, Nuffer M, Gleason SE. Educational methods and technological innovations for introductory experiential learning given the contact-related limitations imposed by the SARS-CoV2/COVID-19 pandemic. Pharmacy (Basel), 2021 Feb 25; 9(1):47. https://doi. org/10.3390/pharmacy 9010047.

17. Pratap A, Neto EC, Snyder P, Stepnowsky C, Elhadad N, Grant D, Mohebbi MH, Mooney S, Suver C, Wilbanks J, Mangravite L, Heagerty PJ, Areán P, Omberg L. Indicators of retention in remote digital health studies: A cross-study evaluation of 100,000 participants. NPJ Digit Med, 2020 Feb 17; 3:21. https://doi.org/10.1038/s41746-020-0224-8.
18. Schlesselman LS. Perspective from a teaching and learning center during emergency remote teaching. Am J Pharm Educ, 2020 Aug; 84(8): ajpe8142. https://doi.org/10.5688/ ajpe8142.

19. Louiselle K, Elson EC, Oschman A, Duehlmeyer S. Impact of COVID-19 pandemic on pharmacy learners and preceptors. Am J Health Syst Pharm, 2020 Jul 7; 77(14):1097-1099. https://doi.org/10.1093/ajhp/zxaa127.

20. Population density of the constituent entities of the Russian Federation as of January 1, 2019. Federal State Statistics Service. Access on: April 16, 2021. https://rosstat.gov.ru/ folder/12781. [Plotnost' naseleniyasub” ektov Rossijskoj Federaciina 1 yanvarya 2019 g. Federal 'nayasluzhbagosudarstvennojstatistiki/ Rezhimdostupa: https://rosstat.gov. ru/folder/12781 (data obrashcheniya 16.04.2021) in Russ]. 